\section{Best Performance Method}

\author{
Glen E. Getz
}

Department of Psychiatry, Allegheny General Hospital, Pittsburgh, PA, USA

\section{Synonyms}

Cognitive potential

\section{Definition}

Neuropsychologists typically do not have an opportunity to evaluate patients before the onset of neurological illness or injury. Judgments about impairment are often made by comparing obtained test scores with estimates of premorbid ability. There are several approaches to estimating premorbid level of ability. One such approach is the Best Performance Method. Using this method, data are collected from multiple sources, including, but not limited to, test scores, observations, interviews, reports from family, and historical data. After the data are collected, the data source that yields the highest level of functioning is the set standard to which all other aspects of functioning are compared. The Best Performance Method assumes that one performance level exists for each person's cognitive abilities. A notable discrepancy between a patient's best and other performances is indicative of neuropsychological impairment. The Best Performance Method also assumes that performance should be consistent across all areas of functioning. For example, very superior intellectual and other abilities would be expected from a patient who has earned a doctoral degree in engineering. The method has been criticized by some who believe that there is a high likelihood of overestimating premorbid ability, and research does not support that performance on cognitive testing is uniform across different tests or cognitive domains. In fact, abnormal performance on some proportion of neuropsychological testing has proven to be psychometrically normal (Binder et al. 2009).

\section{Cross-References}

- Deficit Measurement

$\checkmark$ Premorbid Estimate

$\checkmark$ Premorbid Functioning

- Premorbid Intelligence

\section{References and Readings}

Binder, L. M., Iverson, G. L., \& Brooks, B. L. (2009). TO err is human: "Abnormal" neuropsychological scores and variability are common in healthy adults. Archives of Clinical Neuropsychology, 24, 31-46.

Lezak, M. D., Howieson, D. B., Bigler, E. D., \& Tranel, D. (2012). The rationale of deficit measurement. In Neuropsychological assessment (5th ed.). New York: Oxford University Press.

Mortensen, E. L., Gade, A., \& Reinisch, J. M. (1991). "Best performance method" in clinical neuropsychology. Journal of Clinical and Experimental Neuropsychology, 13, 361-371. 